\title{
Children Flat Foot and Lower Limb Rotational Profile: A Cross-Sectional Descriptive Study
}

\author{
Jemni Sonia1, Lazreg Nadia1, Abid Manel2 , Frioui Samia1', Ben Rejeb Mohamed ${ }^{3}$, \\ Osman Walid ${ }^{4}$, Zaoui Afif', Khachnaoui Faycel ${ }^{1}$ \\ ${ }^{1}$ Department of Physical Therapy and Rehabilitation, Sahloul Hospital, Sousse, Tunisia \\ ${ }^{2}$ High School of Sciences and Technology of Health of Sousse, Sousse, Tunisia \\ ${ }^{3}$ Community and Preventive Medicine Department, Sahloul Hospital, Sousse, Tunisia \\ ${ }^{4}$ Orthopedic Department, Sahloul Hospital, Sousse, Tunisia \\ Email: jemnisonia@hotmail.com
}

Received 17 September 2015; accepted 23 October 2015; published 26 October 2015

Copyright (C) 2015 by authors and Scientific Research Publishing Inc.

This work is licensed under the Creative Commons Attribution International License (CC BY). http://creativecommons.org/licenses/by/4.0/

(c) () Open Access

\section{Abstract}

Flat foot in children is a common deformation, which appears during the first years of life. It requires a rigorous evaluation to rule out congenital or neurological abnormality. It is characterized by a decrease of the plantar concavity indeed collapse of the foot, often associated with other morphostatic deformations. The aim of this study is to find a correlation between the essential flat foot in children and lower limb disorders torsional. It is a cross-sectional descriptive study, recruiting 110 children ( 220 feet) aged between 3 and 6 years old. Each child was given an assessment of the morphology of the foot (Contact Index II...) and lower limb rotational profile (intoeing and femoral antétorsion and tibal torsion). Among 110 children, 21 (19.1\%) have bilateral flat feet and 7 (6.4\%) have unilateral flat feet, associated with an average value of Contact Index II equal to 0.921; the minimum value is 0.880 and the maximum value is 1.17 . All children with flat feet have excessive femoral antétorsion; 45 (92\%) are associated with a hip intoeing and $38(80 \%)$ present an insufficient external tibial torsion. The analysis of multiple regression shows a significantly elevated correlation among the flat foot and excessive internal rotation of the hip $(F=70.36, r=0.77, P<$ 0.001), excessive femoral antetorsion $(F=54.78, r=0.73, P<0.001)$ and insufficient external tibial torsion $(\mathrm{F}=7.79, \mathrm{r}=0.37, \mathrm{P}<0.001)$.

\section{Keywords}

Children, Essential Flat Foot, Femoral Antétorsion, Internal Rotation of the Hip, Tibial Torsion 


\section{Introduction}

Child's flat foot is considered among the most common reasons for pediatric pathology's consultation, often associated with urgent request for treatment. It is a common structural deformation in the pediatric population which appears during the first years of life, but persists in only $3 \%$ of adult population [1]. It is characterized by a decrease of the plantar concavity indeed collapse of the foot, often associated with other morphostatic deformations (rearfoot valgus and forefoot abductus) [1]. Starting from the idea that the valgus flat foot deformities are very common in children with cerebral palsy, which are strongly associated with excessive femoral antetorsion and excessive tibial external rotation, we pose the hypothesis that there is a correlation between the essential flat foot apart from cerebral palsy and torsional abnormalities of the lower limbs. Thus, we aim to highlight a possible relationship among these abnormalities in order to impact and modify the management methods of flat foot.

\section{Material and Methods:}

It is a prospective, cross-sectional descriptive study based on the quantifiable-qualitative approach, conducted among children in primary schools and kindergartens in Sousse, Tunisia (from January to May 2015). For this study, we used a small sample of convenience to mark the initial stages of establishing a normative database of the correlation between the essential foot flat in children and lower limbs twist disorder. We paid special attention to select children from all social backgrounds and to determine a representative sample. Thus the sample of our study involved children split between public and private schools, primary and kindergartens in Sousse. It aims to establish an eventual correlation between the essential flat foot and torsional disorders in children. One hundred and ten children (71 boys and 39 girls) aged between 3 and 6 years (average 4.5) were examined. Teachers and parents have been fully informed about the project beforehand. A demonstration of the test to parents, teachers and children was given. Inclusion criteria are: age between 3 and 6 years and presentation of essential valgus flat foot (soft, collapsible, painless and without functional impairment). Children excluded from this study were those with secondary flat foot (congenital deformities, surgical overcorrection of varus clubfoot, collagen diseases, short Achilles tendon, polimyelities, cerebral palsy, muscular dystrophy, spina bifida, Charcot foot, painful flat foot, and traumatic injuries).

The study involved aspecific pediatric examination including demographic data, balance sheets and tests assessing static disorders of the foot and lower limb.

The pediatric examination included: a review of the plantar skin, the study of mobility and joint laxity of the foot and ankle (metatarsophalangeal and interphalangeal joints, Lisfranc joint, Chopart joint, subtalar joint, ankle joint in dorsiflexion and plantar flexion) [2] [3]. The examination of the hip included the evaluation of intoeing and external rotation (Figure 1) and the femoral antetorsion (Figure 2), performed in two steps to ensure muscle relaxation via aspecific Plexiglas goniometerreferring to Zafiropoulos [4]. It is considered excessive if itis greater than orequal to $30^{\circ}$. We made a comparison between the angles of right and left femoral antetorsion [5]-[7]. The knee's rotary balance [8] [9] was measured with a goniometer to assess the tibial torsion (Figure 3).

Measuring the torsion of the tibialis skeleton [5] [10] [11] was performed with a goniometer in the prone position, knee flexed to $90^{\circ}$ and rearfoot focused, from the angle formed between a line passing through the second metatarsal to the mid-heel and the axis of the femur (Figure 4). A tibial torsion is insufficient if it is less than or equal to $10^{\circ}$. The excessive external tibial torsion is defined by an angle greater than or equal to $50^{\circ}$.

A neurological examination was performed routinely in all children [12] [13] including: assessing voluntary motor rating according to Medical Research Council and the tone, the study of tendon reflexes, plantar reflex

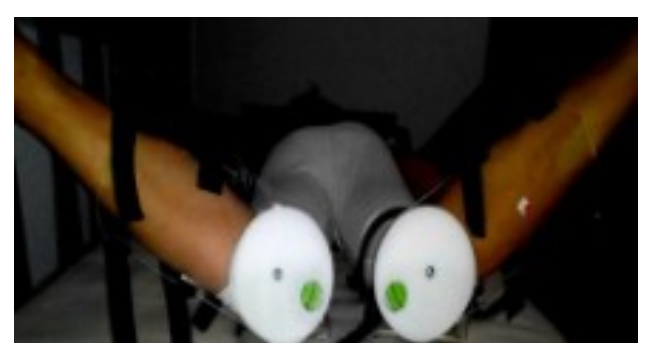

Figure1. Measure of hip rotation with pelvic stabilization. 




Figure2. Measure of femoral antétorsion, while controlling the greater trochanter in the sagittal plane.

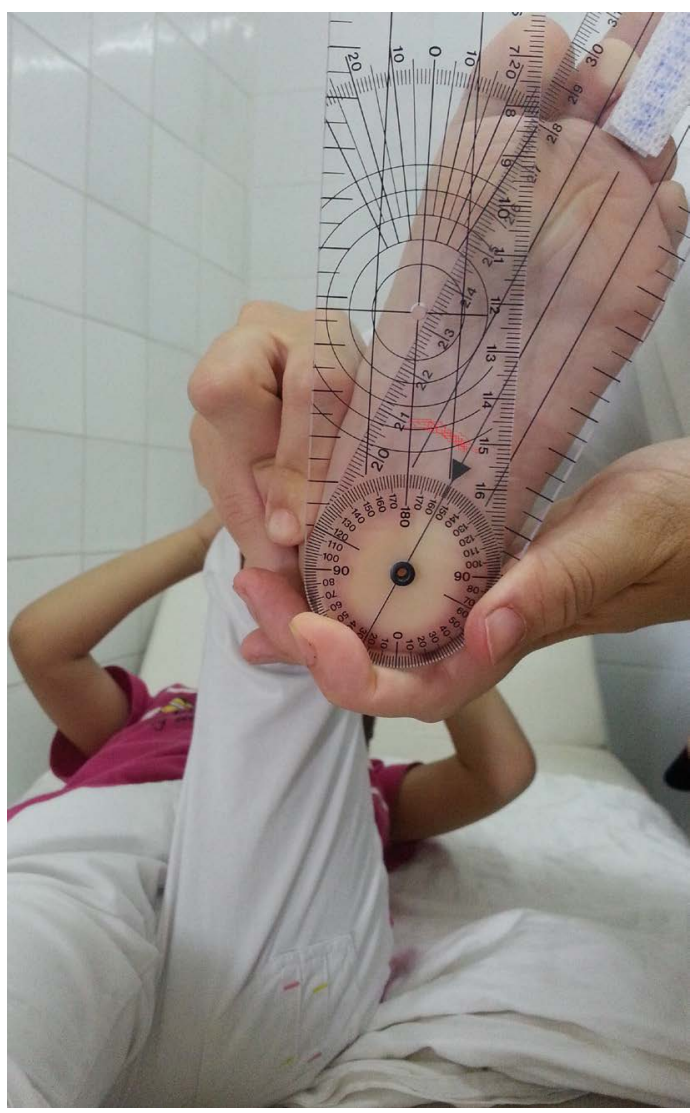

Figure 3. In supine position, measure of external rotation of the knee.

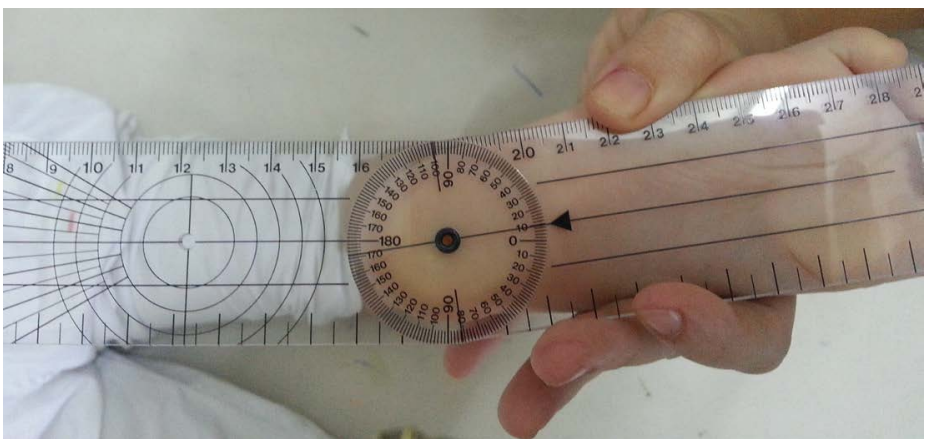

Figure 4. In supine position, external tibial torsion measurement. 
and study of the sensory system. The evaluation of flat foot was performed in charge and in discharge. Two footprints left and right were taken via a podograph to get a permanent image of the plantar surface of the foot. Contact Index II is a clinical parameter measured from a footprint to assess the morphology of the flat foot. A flat foot deformity is defined by a Contact Index II greater than or equal to 0.88 . To measure it, we plotted two straight lines $\mathrm{AB}$ and $\mathrm{CD}$ which are tangent to the outer and inner part of the impression. The axis of the foot $\mathrm{XY}$ connects the middle of the second metatarsal head to the heel. The line KP perpendicular and passing through the center of XY crosses the footprint in two points $\mathrm{N}$ and O. Contact Index II is calculated using the formula NO/KP ratio [14]-[16] (Figure 5). The medial collapse, characterizing flat foot in children, was mentioned [3].

The flat foot deformities were searched such as a valgus deviation of the rearfoot [12] (normal: 5, excessive valgus $>5^{\circ}$, varus $<5^{\circ}$ ), forefoot adductus [17] as classified by Bleck and forefoot abductus [18]. Reducibility of flat foot was evaluated in discharge [19] (in the prone position, feet dangling in the void, a flat foot is said to be reduced, if there is a total or partial disappearance of the collapse of the arch of the foot and the valgus of the rearfoot, on the tiptoe walking [3] (reducible if the foot goes into inversion (Figure 6)), Hintermann Test [3] which reduces the valgus of the rearfoot (in a standing position, an external rotation of the leg is applied searching for a correction of the forefoot's supination) (Figure 7). Then, the Jack Test [3], which assesses the excavation of the middle column of the foot and the calcaneal valgus correction (passive dorsiflexion of the hallux (Figure 8)).

Child's feet orientation when walking, which can be internal or external (physiological) [20] and the frontal morphotype of the knees in charge (normal, genu-valgum or genu-varum) have been clarified.

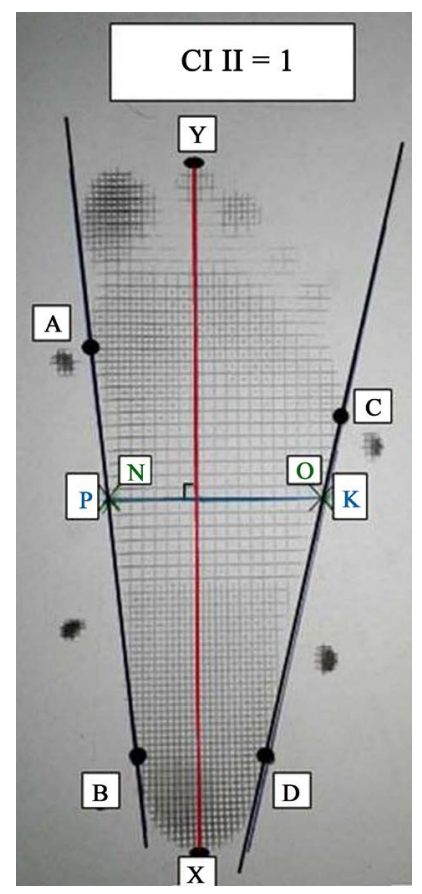

Figure 5. Measuring contact Index II calculated using the formula NO/KP ratio.

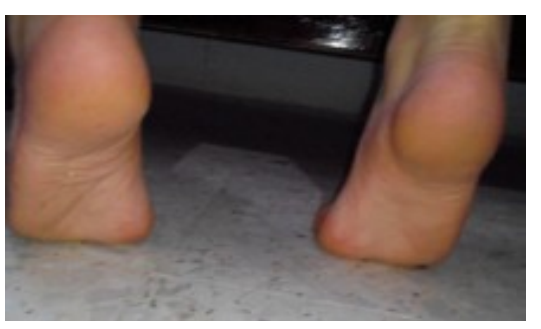

Figure 6. Tiptoe test: disappearance of the collapse of the arch of the foot and the valgus of the rearfoot. 


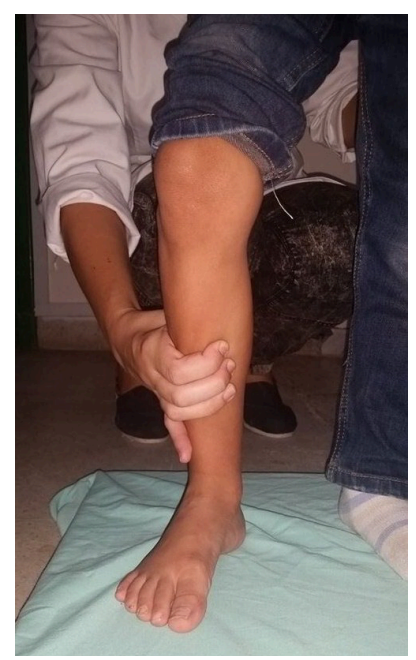

Figure 7. Hintermann test: reducing the valgus of the rearfoot in a standing position, an external rotation of the leg is applied searching for a correction of the forefoot's supination.

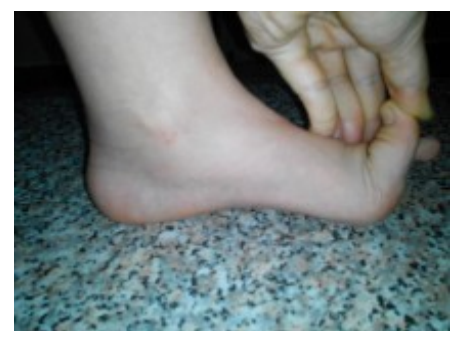

Figure 8. Jack test: the passive dorsiflexion of the hallux brings up an excavation of the middle column of the foot and the correction of calcaneal valgus.

Entering the given analysis was performed using the SPSS version 17 software. We used the student's t-test, the chi2 test, correlation test, univariate linear regression analysis and multiple linear regression. Ethical considerations have been well defined and respected, with the commitment of the research student and responsibility.

\section{Results}

One hundred and ten children were included in this study with male predominance: 71 boys (represents $64.5 \%$ ) and 39 girls (represents 35.5\%). The sex ratio is 1.82. The age varies between 3 and 6 years (average: 4.5 years old).The most represented age group is that between 4 and 5 years $(80 \%)$.

\subsection{Examination of the Foot and Lower Limb in Discharge}

All children had a good quality of the foot pad and bilateral normal joint mobility of all joints of the foot. Comparing the mobility of the hips shows a significant difference $(\mathrm{P}<0.001)$ between the angles of inner and outer rotations of the hips to each side with larger internal rotations. No significant difference $(P=0.928)$ between the angles of right and left femoral antetorsion were identified. There is a significant difference between the internal and external rotation of the knee $(\mathrm{P}<0.001)$ for each of both sides. No significant differences $(\mathrm{P}=0.103)$ between the external tibial torsion angles in right and left. The femoral antetorsion and tibial torsion are significantly related to each other $(\mathrm{P}<0.001)$ (Table 1$)$. Among the children examined, $87.3 \%(\mathrm{~N}=96)$ have a normal-oriented knee, while $12.7 \%(\mathrm{~N}=14)$ have a genu-valgum. The neurological examination is normal for all children.

\subsection{Evaluation's Parameters of Flat Foot}

In our population, 49 feet are flat with an average value of Contact Index II equal to 0.921 , the minimum value 
is 0.880 and the maximum value is 1.171 . However, the others feet are considered normal with a Contact Index II average value was 0.615 . The essential flat foot prevalence among our population $(\mathrm{N}=110$ children) was $25.5 \%$ ( $19.1 \%$ bilateral and $6.4 \%$ unilateral). The inner edge of the foot was not collapsed in the majority of cases $(76.4 \%$ to $79.1 \%$ right and left). The average measurement of valgus angle for the rearfoot for our population is equal to $5.85^{\circ}$ on the right and $5.86^{\circ}$ on the left. Excessive valgus was observed in $50.45 \%$ of the feet. Among our population, $12.7 \%(\mathrm{~N}=14)$ have asymmetrical adductus forefoot. Only 6 children have symmetrical adductus forefeet. All children with an essential flat foot had good reducibility of the deformity comparatively between the two feet, with a total disappearance of the collapse of the medial column, the calcaneal valgus and forefoot abductus in discharge and in dynamic. All flat feet were reducible according to the tipto, Hintermann and Jack tests.

In our study, 164 children $(74.5 \%)$ have normal orientation of the walk while respecting the step angle, but $25.5 \%(\mathrm{~N}=56)$ presents a feet oriented in internal rotation. We found a significant association between the femoral antetorsion and feet's orientation when moving $(\mathrm{p}<0.001)$. Feet oriented in internal rotation are associated with an exaggerated femoral antetorsion in $92.9 \%$ of cases (Table 2). Exaggerated femoral antetorsion, excessive internal rotation of the hip and insufficient external tibial torsion were more frequent in the flat foot (Table 3).

\subsection{Statistical Analysis of the Correlation and the Regression}

Statistical analyzes showed a significant correlation between the internal rotation of the hip and the value of Contact Index II with a Pearson coefficient equal to $0.774(\mathrm{P}<0.001)$. The regression analys is indicates that there is a significant relationship between these two parameters $(\mathrm{F}=70.36, \mathrm{r}=0.77)$. The regression analys is indicates that there is a significant relationship between these two parameters $(\mathrm{F}=54.78, \mathrm{r}=0.73)$.

We reported the existence of a significant negative correlation between the tibial torsion and flat foot with a Pearson coefficient (R) equal to $0.377(\mathrm{P}<0.001)$. The regression analys is indicates that there is a significant relationship between these two parameters $(\mathrm{F}=7.79 ; \mathrm{r}=0.37)$.

The analysis of multiple regression between the internal rotation of the hip, femoral antetorsion, the tibial torsion and flat foot shows that all the conditions are met with a normal distribution of data. We verified that there is no collinearity between variables (FIV $<3.3$ and tolerance $>0.3$ ).

The regression equation is: $\mathbf{Y}=\mathbf{0 . 6 6 7}+\mathbf{0 . 3 9} \mathrm{IRH}+\mathbf{0 . 4 3 8} \mathrm{FAT}-\mathbf{0 . 2 7 5}$ ETT

(Y: flat foot deformity, IR H: internal rotation of the hip, FAT: femoral antetorsion, ETT: insufficient external tibial torsion) (Table 4).

Table 1. Comparison between the angles of antetorsion femoral and tibial torsion $(\mathrm{N}=220)$.

\begin{tabular}{cccccc}
\hline FAT & FAT exaggerated & FAT physiological & Odds ratio & 95\% IC & P value \\
\hline ETT insufficient & $38(38 \%)$ & $16(13.3 \%)$ & 3.98 & {$[2.05-7.73]$} & $<0.001$ \\
ETT physiological & $62(62 \%)$ & $104(86.7 \%)$ & & & \\
\hline
\end{tabular}

FAT: femoral antetorsion; ETT: external tibial torsion; 95\% CI: 95\% confidence interval.

Table 2. Comparison of femoral antetorsion angles depending on the orientation of the feet when walking.

\begin{tabular}{cccccc}
\hline FAT FO & FAT exaggerated & FAT physiological & Odds ratio & 95\% IC & P value \\
\hline With IR & $52(92.9 \%)$ & $4(7.1 \%)$ & 31.41 & {$[10.76-91.69]$} & P $<0.01$ \\
Normal & $48(29.3 \%)$ & $116(70.7 \%)$ & & & \\
\hline
\end{tabular}

FO: Foot Orientation; FAT: Femoral Antetorsion; IR: Internal Rotation of the feet; 95\% CI: 95\% confidence interval.

Table 3. Presentation of the results of statistic data, morphotype of the lower limbs in the frontal and horizontal plane depending on the type of the foot.

\begin{tabular}{|c|c|c|c|c|c|}
\hline Morphotype LL type foot & FAT exaggerated & $\mathrm{IR}>60$ & TTE insufficient & Genu-valgum & Internal orientation foot \\
\hline Flat foot (49) & $49(100 \%)$ & $45(91.8 \%)$ & $38(77.6 \%)$ & $\mathbf{0}$ & $\mathbf{0}$ \\
\hline Normal foot (171) & $51(29.82 \%)$ & $47(27.48 \%)$ & $16(9.35 \%)$ & $28(16.37 \%)$ & $56(32.74 \%)$ \\
\hline
\end{tabular}

Morphotype LL: morphotype lower limbs; FAT: Femoral Antetorsion; ETT: external tibial torsion; IR: hip internal rotation. 
Table 4. Analysis of multiple regression.

\begin{tabular}{|c|c|c|c|c|c|c|c|}
\hline & \multicolumn{2}{|c|}{ Non-standardized coefficient } & \multirow{2}{*}{$\begin{array}{c}\text { Standardized coefficient } \\
\text { Beta }\end{array}$} & \multirow{2}{*}{ t } & \multirow{2}{*}{ Significant } & \multicolumn{2}{|c|}{ Collinearity statistics } \\
\hline & $\mathbf{A}$ & Standard error & & & & Tolerance & VIF \\
\hline Constant & 0.667 & 0.042 & & 15.801 & $<0.001$ & & \\
\hline IRH & 0.002 & 0.001 & 0.390 & 3.236 & 0.002 & 0.418 & 2.394 \\
\hline FAT & 0.005 & 0.001 & 0.438 & 3.729 & 0.001 & 0.440 & 2.274 \\
\hline ETT & -0.008 & 0.002 & -0.275 & -3.370 & 0.002 & 0.910 & 1.099 \\
\hline
\end{tabular}

IRH: internal rotation of the hip; FAT: femoral antetorsion; ETT: insufficient external tibial torsion; VIF: Variation Inflation Factor.

\section{Discussion}

During the early years of child development, parents are concerned about the perception of the shape of the lower limbs and disruption of walking that result. For a normal child, it's an essential flat foot often reducible, flexible and does not cause functional impairment. It tends to improve during growth and persists to adulthood only in $1 \%$ to $2 \%$ of the population [21]. The rotation anomalies of the lower limbs can be femoral, tibial or mixed, resolved at an early age, are limited over time and improve gradually towards the age of 6 years [22].

Experimental evidence made by Arnold et al. [23], in 1997, on a three-dimensional computer model, showed that increase in femoral anteversion by $30^{\circ}-40^{\circ}$ is associated with $40 \%-50 \%$ decrease in the abduction moment arm of the gluteus medius, which becomes ineffective and results in impaired walking. Increased internal rotation of hip by $30^{\circ}$ restored the abduction moment arm of the gluteus medius to $5 \%$ of the normal.

Increased internal rotation of hip is a compensatory mechanism to achieve the abduction moment arm needed for walking. It will develop a compensation mechanism at the tibial segment resulting in a tibial external untwisting.

The impact of lower limb torsion disorders in the foot remains unclear. However, excessive external tibial torsion is usually associated with flat foot and inversely for insufficient tibial torsion and a hollow foot [24] [25]. The age average of our population is 4.5 years $(80 \%$ between $4-5$ years) with a male predominance $(64.5 \%$ boys for $35.5 \%$ girls). To get away from the child's flat foot deformity, we set the minimum age limit to 3 years, age indicated for a spontaneous recovery of the foot. The maximum age limit is fixed to 6 years old because it is considered the most suitable age to treat femoral antetorsion [22]. This age group is comparable to that found in the study by Zafiropoulos in 2009 [4].

For our population, the evaluation of plantar imprints referring to the Contact Index II, allowed to identify a flat foot prevalence of around 25.5\% (19.1\% bilateral and $64 \%$ unilateral). Furthermore, in 2008, Zafiropoulos [4] studied the flat foot deformity in a population of 651 children (1302 feet), aged between 3 and 6 years (mean 4.5). He found that $16.7 \%$ (95) has a flat foot with a Contact Index II greater than or equal to 0.88 (mean 0.93 ).

The distribution of hip rotation in our population showed an asymmetry with a significant difference $(\mathrm{P}<$ 0.001 ) between the inner and outer angles of rotation for both sides. The hip rotation sector lies mainly in internal rotation with an angle average of 55.72 degrees to the right (standard deviation $=11.7$ ) and $55.64^{\circ}$ to the left ( standard deviation $=11.8$ ).

These results are similar to research by Staheli [8] in 1993, which shows in his study that any asymmetry between the hip rotations with internal rotation sector increasing to benefit the external rotation indicates the existence of a hip disorder. Often, it is an excessive femoral antetorsion.

In our study, there is no significant difference $(\mathrm{P}=0.928)$ between the angles of the right and left femoral antetorsion(right: angle average $27.45^{\circ}$ and standard deviation 6.4 , left: angle average $27.44^{\circ}$ and standard deviation 6.5). $46.4 \%$ (51) of the children had an exaggerated antetorsion to the right and $44.5 \%$ (49) to the left.

According to Cahuac JP [7], children who have femoral antetorsion greater than or equal to $30^{\circ}$, have a preponderance of internal rotation compared to external rotation and normal external tibial torsion. The review shows a walk oriented inwards with a concordance of the knee with the axis of the feet. The exaggerated antetorsion mainly affects girls. It is often symmetrical with an inherited trait. It is among the most frequent twisting defects especially around age 5 or 6 years, since it represents $25 \%$ of torsional disorders.

During the growth, there is a decrease of the angle of femoral antetorsion associated with an increase of the external tibial torsion and only $4 \%$ to $10 \%$ will keep those defects of torsion at the end of the growth [7].

The passive rotation area of the knee in our population has an asymmetry of internal and external rotations 
and moves to external rotation (right: average $39.25^{\circ}$ and standard deviation $=7.9$; left: $39.02^{\circ}$ and standard deviation $=7.4)$, with a significant difference between the two $(\mathrm{P}<0.001)$. The assessment of the tibial skeleton's torsion must be associated with the measurement of the passive rotation of the knee. Indeed, external tibial torsion causes an increase in the external sector rotation in favor of internal rotation, and inversely for the internal tibial torsion. At the age of 6 or 7 years, the internal rotation sector gradually decreases and it is no longer associated with the tibial skeleton's orientation [9].

In our study, we found a significant association $(\mathrm{P}<0.001)$ between the femoral antetorsion and external tibial torsion. At the study of Glard [26], in 2012, performed about 1399 children, showed that the femoral antetorsion is negatively correlated to tibial skeleton's torsion.

During our research, we noticed the existence of a medial collapse in all the examined flat feet. It is noted that $50.45 \%$ of the feet have excessive valgus, only $12.7 \%$ of children have a bilateral forefoot adductus and $5.5 \%$ present a bilateral abductus.

Some authors showed that the primitive flat foot is often characterized by the collapse of the internal plantar longitudinal arch in charge, which disappears at the discharge or at the tiptoe walking [27]. An accentuation of calcaneal valgus associated with the onset of a physiological genu-valgus occurs after the age of 2 years [28].

Rushforth [29], in a prospective study of 166 children under 1 year old, has found that 179 feet had a reducible and untreated forefoot's adduction. These children were reviewed between 3 and 11 years. He found a disappearance of the feet deformities in $58 \%$, a slight distortion in $28 \%$, a moderate deformity in $11 \%$ and a severe and fixed deformity in $4 \%$ of the children.

In our study the gait orientation's assessment shows that 74.5\% (164) of children have an external feet orientation and only $25.5 \%$ (56) have an intoeing gait. Our results show the existence of a significant association between the femoral antetorsion and the feet's orientation while walking $(\mathrm{P}<0.001)$.

Zafiropoulos [4] studied the existence of a relationship between the hip intoeing and gait disturbance. Of 651 children examined, $72 \mathrm{had}$ an intoeing gait with high angles of hips intoeing.

In our study $87.3 \%$ of the children examined have normal-oriented knees, $12.7 \%$ have a genu valgum. Researches made by Cahuzac et al. in 1995 [30] and Accadbled et al. in 2007 [25] show that changes in the rotational profile often leads to a change in the alignment of the lower extremities in the frontal plane during growth.

Angular deformities of the knees in the frontal plane is marked by the appearance of a genu varum from birth to the age of 2 years, then it turns into a valgus tibio-femoral from the third year, which is gradually improving during the growth towards puberty [31].

In our study, the statistical results show two high significant positive correlations firstly between high internal hip rotation and Contact Index II, secondly between the exaggerated femoral antetorsion and Contact Index II. However, there is a significant negative correlation between the external tibial torsion and flat foot. That is means that the external tibial torsion default is correlated with the flat foot.

It was found that all children with flat foot have an exaggerated femoral antetorsion. Among 49 flat feet, $91.8 \%$ had high intoeing angles and $77.6 \%$ had an insufficient external tibial torsion.

Our results are similar to those found by Zafiropoulos [4], he proves that there is a positive association between flat foot and excessive hip antetorsion. Indeed, all flat feet are correlated to excessive hip intoeing which indicates the existence of excessive femoral antetorsion.

In 1988, Bollini and Jacquemier [32] showed that themorphology of the foot is relatively associated to the rotational profile of the lower member. They defined four clinical features:

- An exaggerated femoral antetorsion with insufficient external tibial torsion are accompanied by a false flat valgus foot.

- An exaggerated femoral antetorsion with exaggerated external tibial torsion are accompanied by a normal or a false hollow foot.

- A low femoral antetorsion and insufficient tibial torsion are accompanied by anormal foot.

- A low femoral antetorsion and exaggerated external tibial torsion are accompanied by a flat foot.

The small sample size and the geographical restrictions to Sousse region of Tunisia were represented as a two limitations in this study that decrease the validity of generalizing this normative data to the pediatric population with respect to the torsional changes of the lower extremity long bones and the morphofunctional characteristics of flat foot in children.

Further prospective research including children of age groups above 6 is recommended to establish the qualitative and quantitative progression of this relationship and highlight the future direction of management. In addi- 
tion, it is suggested to involve a larger sample size and more diverse demographic region in order to increase the validity of making generalizations to the pediatric population.

\section{Conclusion}

The essential flat foot is a common benign disease in children. His spontaneous evolution tends towards the correction and improvement of various associated morphostatic disorders, such as the medial collapse, the accentuated calcaneus valgus and the fore foot abductus. The hypothesis of a possible association between the essential flat foot and torsional disorders of the lower limbs is a subject evoked by several authors. Our descriptive study was conducted on 110 children in primary schools and kindergartens in Sousse (Tunisia), aged between 3 and 6 years old. We found a prevalence of flat foot around $25.5 \%$ and a significant correlation between the essential flat foot and overlying rotational abnormalities. Indeed, we found a positive correlation between the exaggerated femoral antetorsion and flat foot on the one hand, and a positive correlation between the high hip intoeing and the flat foot on the other hand. However, we found a negative correlation between insufficient external tibial torsion and flat foot.

\section{Conflict of Interest}

No benefits in any form have been received or will be received from a commercial party related directly or indirectly to the subject of this article. No funds were received in support of this study. The authors confirm that this article content has no conflicts of interest.

\section{References}

[1] Khouri, N. (2008) Pied plat idiopathique de l'enfant et de l'adolescent. Conférence d'enseignement 2008. Cahier d'enseignement de la SOFCOT no 97. Elsevier, Paris, 197-205.

[2] Dalarque, A., Demortière, E., Collado, H., Mesure, S., Rubino, T. and Gonzalez, J.F. (2006) Bilan articulaire de la cheville et du pied chez l'adulte. EMC (Elsevier Masson SAS, Paris), Podologie. (27-010-A-25), 13 p.

[3] Wicart, P. and Toullec, E. (2010) Pied plat valgus idiopathique. In: Seringe, R., Besse, J.-L. and Wicart, P., Eds., Les déformations du pied de l'enfant et de l'adulte (à l'exclusion de l'avant-pied). Cahiers d'enseignement de la SOFCOT, Elsevier Masson SAS, Paris, 3-315. http://dx.doi.org/10.1016/b978-2-84299-912-4.00027-4

[4] Zafiropoulos, G., Pasad, K.S.R.K., Kouboura, T. and Danis, G. (2009) Flat Foot and Femoral Anteversion in Children-A Prospective Study. The Foot, 19, 50-54. http://dx.doi.org/10.1016/j.foot.2008.09.003

[5] Zeller, R. and Seringe, R. (1994) Troubles statiques des membres inférieurs. Journal de Pédiatrie et de Puériculture, 5, 72-77.

[6] Caton, J., Neyret, P., Falise, C. and Ait Si Selmi, T. (1997) Anomalies de torsion du squelette au membre inférieur. Encycl. Med. Chir (Elsevier, Paris), Appareil locomoteur, 15-392-A, 10 p.

[7] Cahuzac, J.P. (2008) Vices de torsion des membres inférieurs. Société Française d'Orthopédie Pédiatrique (SOFOP), 3, 395-397.

[8] Staheli, L.T. (1993) Rotational Problems in Children. Journal of Bone and Joint Surgery (American), 75, 939-949.

[9] Fenoll, B., Senab, C. and Cadilhac, C. (2001) Les “pieds qui tournent”. In: Moulies, D. and Tanguy, A., Eds., chirurgie et orthopédie du pied de l'enfant. Monographie du groupe d'étude en orthopedie pédiatrique, Sauramps medical, Montpellier, 349.

[10] Taussig, G. (1995) Les anomalies de rotation des membres inférieurs chez l'enfant. Journal de Pédiatrie et de Puériculture, 6, 131-136.

[11] Viehwegera, E., Bérardb, C., Berruyerb, A. and Simeonic, M.-C., Groupe Varax (2007) Bilan articulaire des membres inférieurs d'un enfant atteint d'une infirmité motrice cérébrale. Annales de réadaptation et de médecine physique, 50, 258-265.

[12] Goldcher, A. (2012) Podologie. 6 ères edition, Elsevier Masson SAS, Paris.

[13] Denormandie, P., Lonjon, G. and Seringe, R. (2010) Testing musculaire du pied. In: Seringe, R., Besse, J.-L. and Wicart, P., Eds., Les grandes déformations du pied de l'enfant et de l'adulte (à l'exclusion de l'avant-pied), Elsevier Masson SAS, Paris, 41-45. http://dx.doi.org/10.1016/b978-2-84299-912-4.00014-6

[14] Didia, B.C., Omu, E.T. and Obuoforibo, A.A. (1987) The Use of Footprint Contact Index II for Classification of Flat Feet in a Nigerian Population. Foot \& Ankle International, 7, 285-289. 
http://dx.doi.org/10.1177/107110078700700504

[15] Quamra, S.R., Deodhar, S.D. and Jit, I. (1980) Podographical and Metrical Study for Pes Planus in a Northwestern Indian Population. Human Biology, 52, 435-445.

[16] Maes, R., Dojcinovic, S., Andrianne, Y. and Burny, F. (2006) Etude de la voute plantaire: Corrélations entre des paramètres podométriques et radiologiques. Revue Médicale de Bruxelles, 27, 429-422.

[17] Bleck, E.E. (1983) Metatarsus Adductus: Classification and Relationship to Outcomes of Treatment. Journal of Pediatric Orthopaedics, 3, 2-9. http://dx.doi.org/10.1097/01241398-198302000-00002

[18] Toullec, E. (2012) Pied plat de l'adulte. EMC (Elsevier Masson SAS), Paris, Podologie (27-060-A-10).

[19] Piat, A. (2000) Pied palt valgus. EMC (Elsevier Masson SAS), Paris, Podologie (27-060-A-10), 7 p.

[20] Wicart, P. and Maestro, M. (2010) Examen clinique du pied. In: Seringe, R., Besse, J.L. and Wicart, P., Eds., Les déformations du pied de l'enfant et de l'adulte (à l'exclusion de l'avant-pied), Elsevier Masson SAS, Paris, 31-39. http://dx.doi.org/10.1016/b978-2-84299-912-4.00013-4

[21] Cigala, F. and Capuano, L. (2010) Histoire naturelle du pied plat valgus idiopathique. In: Diméglio, A., Ed., Le pied de l'enfant et de l'adolescent. Pathologie locomotrice et médecine orthopédique 36, Elsevier Masson SAS, Paris, 448.

[22] Turek, S. (1984) Orthopaedics: Principles and Their Application. Lippincott, Philadelphia, 1236-1237.

[23] Arnold, A.S., Komattu, A.V. and Delp, S.L. (1997) Internal Rotation Gait: A Compensatory Mechanism to Restore Abduction Capacity Decreased by Bone Deformity? Developmental Medicine \& Child Neurology, 39, 40-44. http://dx.doi.org/10.1111/j.1469-8749.1997.tb08202.x

[24] Lerat, I.L. and Taussing, G. (1982) Les anomalies de rotation des membres inférieurs. Revue de Chirurgie Orthopédique, 68, 1-74.

[25] Accadbled, F.M.C. and Cahuzac, J.P. (2007) Anomalies rotationnelles des membres inférieurs che l'enfant. EMC (Elsevier Masson SAS), Paris.

[26] Glard, Y. (2012) Relation entre antétorsion fémorale et torsion tibiale chez l'enfant: À propos de 1399 cas. Revue de Chirurgie Orthopédique et Traumatologique, 98, S298. http://dx.doi.org/10.1016/j.rcot.2012.08.061

[27] Harris, R.I. and Beath, T. (1948) Hypermobile Flat Foot with Short Tendo Achillis. The Journal of Bone and Joint Surgery, American Volume, 30, 116-138.

[28] Tachdjian, M.O. (1990) Flexible pesplanevalgus. In: Pediatric Orthopaedics, 2nd Edition, Saunders, Philadelphia, 8385.

[29] Rushforth, G.F. (1978) The Natural History of Hooked Forefeet. The Journal of Bone and Joint Surgery, British Volume, 60, 530-532.

[30] Cahuzac, J.P., Vardon, D. and Sales de Gauzy, J. (1995) Development of the Clinical Tibiofemoral Angle in Normal Adolescents. A Study of 427 Normal Subjects from 10 to 16 Years of Age. The Journal of Bone and Joint Surgery, British Volume, 77, 729-732.

[31] Tachdjian, M. (1990) Torsional (Or Rotational) Déformities of Lower Limb. WS \& Company Ltd., Scarborough, ON.

[32] Bollini, G. and Jacquemier, M. (1988) Physiologie du développement des membres inférieurs et conséquences sur le pied. Chirurgie et Orthopédie du pied. Sauramps Medical. 